\title{
One size will never fit all: the future of research in pediatric transfusion medicine
}

\author{
Cassandra D. Josephson', Traci Heath Mondoro², Daniel R. Ambruso ${ }^{3}$, Rosa Sanchez ${ }^{4}$, Steven R. Sloan ${ }^{5}$, Naomi L. C. Luban ${ }^{6}$ and \\ John A. Widness ${ }^{7}$
}

There is concern at the National Heart, Lung, and Blood Institute (NHLBI) and among transfusion medicine specialists regarding the small number of investigators and studies in the field of pediatric transfusion medicine (PTM). Accordingly, the objective of this article is to provide a snapshot of the clinical and translational PTM research considered to be of high priority by pediatricians, neonatologists, and transfusion medicine specialists. Included is a targeted review of three research areas of importance: (i) transfusion strategies, (ii) short- and longterm clinical consequences, and (iii) transfusion-transmitted infectious diseases. The recommendations by PTM and transfusion medicine specialists represent opportunities and innovative strategies to execute translational research, observational studies, and clinical trials of high relevance to PTM. With the explosion of new biomedical knowledge and increasingly sophisticated methodologies over the past decade, this is an exciting time to consider transfusion medicine as a paradigm for addressing questions related to fields such as cell biology, immunology, neurodevelopment, outcomes research, and many others. Increased awareness of PTM as an important, fertile field and the promotion of accompanying opportunities will help establish PTM as a viable career option and advance basic and clinical investigation to improve the health and wellbeing of children.

\section{INTRODUCTION}

The Transfusion Medicine/Hemostasis Clinical Trials Network (TMH CTN) was created by the National Heart, Lung, and Blood Institute (NHLBI) in 2002 and is charged with performing trials in children and adults. While there were adequate numbers of pediatric hematologists to put forward ideas for practice-changing studies; it was apparent that there were few investigators focused on PTM. This "failure to thrive" diagnosis in the field of PTM prompted action by the NHLBI in 2005 to form a working group that resulted in curriculum development grants named the Pediatric Transfusion Medicine Academic Awardees (PTMAA) program. Another change that nourished the field of PTM was the American Board of Pathology's move to allow board eligible pediatricians to apply directly into transfusion medicine fellowship after residency. These developments brought awareness to PTM as a field and defined a path for young investigators who wish to focus on PTM.

In 2008, as the PTMAA investigators began to "come of age" they sponsored a working group, with an emphasis strictly on clinical and translational research gaps in the field of PTM. The working group identified three major areas of concern: (i) transfusion strategies; (ii) short- and long-term consequences of transfusion; and (iii) transfusion-transmitted diseases as they relate to neonatal and pediatric patients. In 2009, NHLBI convened a State of the Science Symposium on Clinical Trials in Transfusion Medicine. The aim of this symposium was to identify phase II and III clinical trials that could have a significant impact in advancing transfusion therapies in the next 10 years. Out of the 24 concepts presented, three neonatal/ pediatric trials were prioritized within the top ten, selected by an external panel of transfusion medicine experts (1). Since then, NHLBI has initiated less formal meetings where clinical investigators from many disciplines gather to discuss PTM and research gaps within this small field. Future meetings on the State of the Science in transfusion medicine will continue to assess the field of PTM and recommend studies to be performed. The objective of this article is to provide a snapshot of the clinical and translational research thought to be of highest priority by pediatricians, neonatologists, and transfusion medicine specialists.

\section{TRANSFUSION STRATEGIES}

\section{Neonatal Transfusions}

In the United States, determining the number of transfusions administered to neonates is difficult; however, an estimate of the number of red blood cell (RBC) transfusions given to premature infants has been derived by extrapolating from the University of Iowa's transfusion practices to the US Statistics of Live Births in 2000. According to this estimate, 41,699 of the 56,350 infants of very low birth weight (VBLW, $<1,500 \mathrm{~g}$ ) were transfused with RBCs. The average was three transfusions per

\footnotetext{
'Department of Pathology and Laboratory Medicine and Center for Transfusion and Cellular Therapies, Emory University School of Medicine, Atlanta, Georgia; ${ }^{2}$ National Heart, Lung, and Blood Institute, National Institutes of Health, Bethesda, Maryland; ${ }^{3}$ Bonfils Blood Center, Aurora, Colorado; ${ }^{4}$ Blood Systems Research Institute, San Francisco, California; ${ }^{5}$ Joint Program in Transfusion Medicine, Children's Hospital, Boston, Massachusetts; ${ }^{6}$ National Children's Medical Center, Washington, DC; ${ }^{7}$ Department of Pediatrics, University of lowa, lowa City, lowa. Correspondence: Cassandra D. Josephson (cjoseph@emory.edu) 
infant, totaling to $>250,000$ transfusions in VLBW infants for that year (2). As with RBC transfusions, when platelet transfusion data from the University of Iowa is extrapolated to US neonatal intensive care units admissions, it is estimated that neonates in the United States receive 80,000 platelet transfusions per year (J.A. Widness, personal communication).

Neonatal RBC transfusions. In addition to the paucity of data for transfusions to premature infants there is a lack of consensus on the optimal hemoglobin levels at which neonates should be transfused. The concern is that over-transfusion may pose dangers for the neonate because microvascular blood flow, tissue perfusion, and conversely, oxygenation can be compromised by high hemoglobin levels. Two RBC transfusion threshold trials $(3,4)$ in this population and their subsequent follow up studies (5-7) have been published with discordant results. Both trials independently suggest, but neither proves, that a higher hemoglobin transfusion threshold confers neuroprotection. A definitive randomized clinical trial (RCT), Transfusion of Prematures, or TOP, began in 2013 that will randomize 1,824 extremely low birth weight (ELBW, <1,000 g) infants to a liberal or restrictive RBC transfusion regimen. The thresholds are based on the presence of respiratory support and postnatal age, with the primary outcome of death or significant neurodevelopmental impairment in survivors at 22-26 mo corrected gestational age.

Another high interest RBC transfusion topic in neonates is whether or not age of the RBCs has an effect on clinical outcomes. A Canadian trial, the Age of Red Blood Cells in Premature Infants, was recently completed (8). In Age of Red Blood Cells in Premature Infants, 450 VLBW infants were randomly assigned to either RBCs stored $\leq 7 \mathrm{~d}$ (mean, $5.1 \mathrm{~d}$ ) or to standard issue RBC with storage ranging from 2 to $42 \mathrm{~d}$ (mean, $14.6 \mathrm{~d}$ ). The primary endpoint was a composite outcome of necrotizing enterocolitis (NEC), intraventricular hemorrhage (IVH), bronchopulmonary dysplasia, and retinopathy of prematurity at 30 and $90 \mathrm{~d}$. This study suggests that the age of RBCs in VLBW infants studied does not affect common morbidities of prematurity. Nonetheless, there remains interest among US investigators to perform a trial where VLBW infants are randomized to receive RBCs stored $\leq 7 \mathrm{~d}$ or $>14$ d (C.D. Josephson, personal communication). A new study would supplement the knowledge gained in Age of Red Blood Cells in Premature Infants by providing a comparison of the differences in RBC processing between Canada and the United States, provide a greater separation of the RBC age in the treatment arms, and examine liberal vs. restrictive transfusion strategies focusing on length and degree of anemia (9).

Neonatal platelet transfusions. There are few evidence-based studies of platelet transfusions in neonates with the association between thrombocytopenia and bleeding remaining unclear. In one study with 58 infants, only two infants with IVH had low platelet counts and prolonged bleeding, and two more had minor decreases in platelet counts but normal bleeding times (10). Another study with 97 subjects found an association between prolonged bleeding times and a platelet count $<100,000$, but this association was not linear or precise (11). This study agreed with a large (1,283 subjects) study (12) and found a correlation between neonatal thrombocytopenia and higher IVH incidence where almost half of the thrombocytopenic infants had IVH. However, another study with 302 subjects showed no association between platelet count and IVH incidence; more than half the patients had normal platelet counts (13). All these studies focused on preterm infants in the first week of life. Whereas, in a study of 120 full-term infants with alloimmune thrombocytopenia (14), 103 had severe thrombocytopenia. Seventeen of 103 infants developed intracranial hemorrhage, and 13 infants had neurologic sequelae with platelet counts below $50 \times 10^{9} / 1$ that persisted throughout the $2.5 \mathrm{y}$ follow-up period.

Clearly, important pediatric and neonatal platelet transfusion management questions remain. Among these are (i) should prophylactic transfusions be administered based on platelet count and clinical condition or should they only be administered therapeutically for significant bleeding and (ii) which platelet product(s) are optimal for which clinical thrombocytopenic situations. The only RCT (15); as well as a retrospective review (16) both found that transfusing VLBW with platelet counts of $60 \times 10^{9} / 1$ or lower in the first week did not reduce the frequency or severity of IVH. As a result, many studies continue to report large variability in the practice of platelet transfusions in the NICU (16-19). Several studies have correlated the number of platelet transfusions with higher morbidity and mortality in NICU patients $(18,20-22)$, but most did not evaluate the severity of illness before platelet transfusion. It remains unclear whether platelet transfusions represent a marker of illness severity or contribute directly to morbidity and mortality. A two-arm RCT to study the incidence of severe bleeding in thrombocytopenic neonates treated with a restrictive vs. liberal platelet transfusion approach has been proposed to address this question (1). The primary endpoint will be the incidence of severe bleeding, as well as the role of prophylactic platelet transfusions.

\section{Pediatric Transfusions}

There are 250,000 admissions in 300 US pediatric intensive care units (PICUs) per year and $50 \%$ of the children receive at least one RBC transfusion (23). Transfusions in children are given with few evidence-based guidelines and many practices are based on historical norms from adults rather than evidence from pediatric patients. Published surveys have demonstrated that the frequency of RBC transfusion varies widely at children's hospitals in the United States and Canada (24). The results and recommendations for transfusion practice based on trials designed for an adult population should not be automatically adapted to a pediatric population.

Pediatric RBC transfusions. Lacroix and colleagues reported a multicenter RCT (25) testing the hypothesis that liberal and restrictive RBC transfusion programs would be equivalent. Equivalence was defined as a $<10 \%$ difference in the 


\section{Pediatric transfusion medicine research $\quad$ Review}

development of new or progressive multi-organ dysfunction, the primary outcome of the trial. By intention-to-treat analysis, rates of new or progressive multi-organ dysfunction were $12 \%$ in both groups. The investigators concluded that in stable, critically ill children a hemoglobin threshold of $7 \mathrm{~g}$ per deciliter for $\mathrm{RBC}$ transfusion can decrease $\mathrm{RBC}$ transfusion requirements without increasing adverse outcomes. To examine the effect of the age of $\mathrm{RBC}$ on outcomes in the pediatric intensive care unit, the Age of Blood in Children in Pediatric Intensive Care Units (ABC-PICU) study (a RCT has been funded by NHLBI and the Canadian Institutes of Health Research) and will begin enrollment in 2014. The study will randomize 1,502 critically ill children to either RBC units stored for $<7 \mathrm{~d}$ or standardissue RBC units. The, primary outcome will be new or progressive multi-organ dysfunction at $28 \mathrm{~d}$ post-enrollment (26).

Pediatric platelet transfusions. Clinical studies and trials in pediatric platelet transfusion are scarce. A Pub Med search using the terms "pediatric platelet transfusion" yields 564 references published between 1957 and 2014. Of these 564 papers, only ten are focused on platelet transfusions in general pediatric populations. Twenty-three of the papers investigated neonatal transfusions, and 17 reported on platelet transfusions in oncology patients as adjunct to stem cell transplantation or chemotherapy. The most recent disease-agnostic paper from 2007 found that there is wide variability in transfusion practices across the 35 children's hospitals that participated in the study (27). The accompanying editorial emphasized the differences found with respect to the ethnicity of the patients as well as the variations in practice and called for definitive trials to be performed in this area (28).

\section{SHORT- AND LONG-TERM CLINICAL CONSEQUENCES}

Pediatric blood recipients have higher post-transfusion survival rates compared to adult blood recipients $(29,30)$. Given longer post-transfusion survival rates and developmental immaturity of the immune system, blood brain barrier, and physiology in general, it is likely that neonatal and young pediatric blood recipients are at greater risk than older transfusion recipients for long-term adverse outcomes from both known and currently unknown adverse effects of transfusion. In this section, three examples are discussed: NEC, RBC alloimmunization, and transfusion-associated microchimerism (TA-MC).

\section{Transfusion Related-Necrotizing Enterocolitis}

Approximately $11 \%$ of premature infants $<29 \mathrm{wk}$ gestation will develop NEC (31) and the mortality rate is $20-30 \%$ (32). Infants who survive NEC have long-term complications, including short bowel syndrome, impaired growth, and (neuro-)developmental impairment (33). The disease can frequently progress from early clinical symptoms to intestinal necrosis within hours, limiting the efficacy of therapeutic intervention. Strategies to prevent NEC are a primary focus of research investigations although a limited understanding of the etiology of NEC has slowed these efforts (34). Researchers have identified several factors contributing to the development of NEC including: enteral feeding, gastrointestinal bacterial colonization, gut motility, pro-inflammatory propensity of the immature gut and impaired intestinal blood flow (35-38). The multifactorial nature of the disease suggests that preventative efforts would be more successful if they targeted multiple components, including the emerging risk factor of RBC transfusion and its potential involvement in the pathogenesis of NEC. Investigating the role of RBC transfusion is relevant given the finding that $\sim 25-38 \%$ of NEC cases in retrospective studies have been reported to occur within $48 \mathrm{~h}$ of RBC transfusion (39-41). A recent meta-analysis of these studies emphasized that $\mathrm{RBC}$ transfusion is an independent risk factor for transfusion related NEC and the need for prospective investigations of this devastating clinical entity (42). Future studies should include comparisons of transfusion volumes, irradiated blood products vs. non-irradiated products, age of blood transfused, time of transfusion especially in relation to feeding, and simultaneous feeding vs. withholding of feeding until after transfusion is complete (43).

\section{RBC Alloimmunization}

Post-transfusion alloimmunization to minor RBC antigens occurs infrequently in neonates and more commonly in pediatric patients $(15,44)$. RBC alloimmunization arises in certain transfusion recipients exposed to foreign minor RBC antigens such as RhD. Memory lymphocytes induce an immune response that persists throughout life whereas the antibodies that cause the hemolysis often wane over years to undetectable levels by current laboratory methods (a screen which is an indirect antiglobulin test (45)). In females this sensitization can have long-term complications with potential deleterious effects on future pregnancies such as alloimmune hemolytic disease of the fetus and newborn, including fetal demise (46). These children may also experience delayed hemolytic transfusion reactions in the short and long term which can also have fatal consequences. Thus, pediatric patients are especially susceptible to complications of RBC alloimmunization, due to the long lifespan of the patient and the waning detectability of clinically significant antibodies (47).

In addition to identifying who is at the highest risk for clinical consequences from post-RBC transfusion antibody production, it is important to recognize which recipients are more likely to develop antibodies to RBC antigens. One approach to indirectly address this question has been to examine alloimmunization frequencies in patients who received multiple transfusions for hemoglobinopathies (i.e., sickle cell disease (SCD) or thalassemia). RBC alloimmunization rates in these populations are between $16-70 \%$ in some studies (48-52). Theoretically, one approach to minimize alloimmunization of susceptible individuals would be to prospectively match recipients for multiple minor RBC antigens. Although the efficacy of this approach has not been rigorously tested, it is practiced in some patient populations, such as patients with SCD. In some medical centers this appears to reduce alloimmunization $(53,54)$. Future research into these questions could lead to individually tailored RBC transfusion therapy, especially 
with the use of molecular based testing for minor RBC antigen matching between donor and recipient $(55,56)$.

\section{Transfusion-Associated Microchimerism}

Microchimerism (MC) is the persistence and engraftment of $<5 \%$ of non-self cells circulating in the host. MC occurs naturally during pregnancy with feto-maternal and twinning blood exchange, but MC can also be intentionally induced through hematopoietic stem cell transplantation (57-59). The persistence of donor leukocytes after allogeneic blood transfusion is referred to as transfusion-associated microchimerism (TAMC) and has been demonstrated in $10-20 \%$ of adult patients following transfusion for traumatic injury (60). The development of TA-MC in pediatric blood recipients is important since a majority of transfused children will survive to adulthood. While gamma irradiation may reduce the number of persistent donor leukocytes, there is no universally accepted "standard of practice" for transfusion of gamma irradiated blood in children. In a recent study of 207 adult and 202 pediatric female medical and surgical recipients of leukoreduced and irradiated RBCs and platelets, persistence of TA-MC (Y-chromosome) was not demonstrated at 4- and/or 8-wk after transfusion (61). This suggests that pediatric blood recipients of non-irradiated and shorter storage aged blood components are not at increased risk for development of TA-MC.

Marshall et al. evaluated ten hemoglobinopathy patients for TA-MC; four patients (three SCD and one thalassemia) demonstrated transient MC 22-36 d post-transfusion (62). Further evaluation of persistent MC is warranted in hemoglobinopathy blood recipients to determine whether TA-MC represents a harmful or beneficial consequence of blood transfusion. If persistent TA-MC is demonstrated in a pediatric patient population, the next step is to study the clinical, immunologic, and blood product characteristics associated with the development of TA-MC and to monitor for long-term clinical consequences, e.g., chronic graft-versus-host disease or autoimmune conditions.

\section{INFECTIOUS TRANSFUSION-TRANSMITTED DISEASES Blood Safety}

Surveillance, donor selection, testing, and hemovigilance have led to a low risk for HIV and HCV of approximately one infection in 1-1.5 million units transfused (63). Current blood safety has been maintained by introducing new donor screening questions and new tests are added as new agents and technologies appear (64). To overcome the lack of a formal hemovigilance system, the American Association of Blood Banks and the Centers for Disease Control have recently formed a publicprivate partnership to implement a Biovigilance Network to include an infectious diseases arm specifically related to the investigation and confirmation of transfusion transmitted infectious diseases (65).

\section{Infectious Diseases in PTM}

The efficacy of transfusion in achieving homeostasis must be balanced against the risk of harm. Infants and children have unique issues affecting this balance, including immature immune systems, anatomic issues such as small passages, rapid cell-growth rates, and first exposures. Through adaptive immunity, neonates primarily receive immunoglobulin $\mathrm{G}$ passively from their mothers, and although they have a complete repertoire of lymphocyte subpopulations, their cytokine and chemokine production is limited. Infectious diseases of particular concern due to morbidity and mortality implications in neonatal and pediatric populations are cytomegalovirus (CMV), Babesia, and dengue. The current strategy of using CMV seronegative units combined with the removal of latently infected leukocytes is effective, but there are still reports of breakthrough cases of transfusion-transmitted CMV (66), especially in immuno-incompetent premature infants and immunocompromised primary immunodeficiency and oncology/stem cell transplant recipients. Babesia is a tickborne parasite that can be transmitted through transfusion or transplacentally (67). Currently, there is no licensed test to screen blood donors for Babesia; however, the Rhode Island Blood Center is testing the use of serology and nucleic acid testing for neonates and pediatric SCD patients receiving exchange transfusions (68). Lastly, dengue is now endemic in over 100 countries reaching epidemic proportions in some Asian and Latin American countries. There is no vaccine and prevention depends solely on vector control (69).

\section{Pathogen Reduction in PTM}

An important strategy to reduce the risk of transfusion-associated bacteremia and other infectious diseases, is pathogen reduction technology. Studies in which platelet components have been cultured at outdate have shown that $\sim 1$ in 1,500 apheresis platelet components contain bacteria (70-72). Although the safest and most effective blood products are desired for all patients, pediatric transfusion safety is different in several key respects. Any potential gain in transfusion safety for this population may result in many more disease-free years of life compared to adults. This makes the calculation of costeffectiveness in quality-adjusted life years gained more compelling for children who receive transfusions.

There are two pathogen reduction methods for cellular products that are under investigation in the United States, and both are effective against bacteria, enveloped and non-enveloped viruses, and parasites. The first of these is a psoralenbased compound that intercalates with the nucleic acid of the pathogen upon activation by ultraviolet light (73). Efficacy was demonstrated in a RCT that allowed enrollment of subjects $6 \mathrm{y}$ and older, but only six subjects aged 16 y or younger were enrolled out of 654 subjects (74). Psoralen treated platelets have been tested in Alsace, France to support pediatric and adult patients with Glanzmann's thrombasthenia (unpublished data). The other technology uses riboflavin and UV light to intercalate with nucleic acids (75). In addition to pathogen reduction, this technology appears to reduce alloimmunization and transplant rejection in an animal model (76) and was effective in an RCT (77). All these methods cause perturbation to the cell membrane raising concerns about introduction 


\section{Pediatric transfusion medicine research $\quad$ Review}

of new chemical entities into the blood, short- and long-term toxicities, and effects on cell quality and transfusion efficacy.

\section{INNOVATIVE STRATEGIES TO PROMOTE RESEARCH IN PEDIATRIC TRANSFUSION MEDICINE}

As described herein, recognition of gaps in evidence-based practices for neonatal and pediatric transfusion has stimulated creative strategies to accomplish needed studies. For example, the sub-analysis paper for the platelet dose study (78), which included over 200 children in a 1,350 patient RCT performed by the TMH CTN, yielded information that distinguished the bleeding patterns and amount of bleeding in children as different from adults with hypoproliferative thrombocytopenia. The inclusion of children in this study was important as it revealed the first new information about platelet transfusion in over $30 \mathrm{y}$ within the era of modern chemotherapy and cancer treatment in children. However, platelet dose was not powered to detect differences in the pediatric subpopulation so these findings are still preliminary, but it is clear that a separate study, with a large sample size, is necessary to provide definitive evidence.

One innovative strategy to study large numbers of children is by investigators collaborating with established networks such as the National Institute of Child Health and Human Development Neonatal Research Network which has worked with NHLBI to perform the ongoing TOP trial, deemed in the State of the Science meeting to be one of the most important phase III trials needed in the next decade. Another innovative tact to accomplish large RCTs is by building a grass roots network as the pediatric critical care community has done with the Blood Net program (http://www.bloodnetresearch. org/) and the Pediatric Acute Lung Injury/Sepsis Investigators (http://www.palisi.org/) network. With this infrastructure the network investigators were able to secure funding for enough centers to correctly power different study questions. One tangible result of this collaboration is the ABC-PICU trial described earlier in this review.

Funding for pragmatic RCTs is also now possible through the newly established Federal institute, Patient Centered and Outcomes Research Institute (PCORI) (http://www.pcori.org), which is suitable for some of the research suggested in this review. Specifically, research designs and methodology related to comparative effectiveness, also within PCORI's mission may answer certain questions related to blood utilization's impact on pediatric outcomes; and safe platelet transfusion therapies in premature infants.

In conclusion, this is an exciting time for the field of PTM. Multiple and varied opportunities exist for investigators from various fields to use PTM as a model system to create an evidence-based foundation for clinical decision making while engaging scientific disciplines such as, immunology, cell biology, infectious disease, microbiology, metabolic biochemistry, pharmacology, and epidemiology.

\section{ACKNOWLEDGMENTS}

We gratefully acknowledge the input, advice, and knowledge gained from many intensive discussions with the following: Raymond P Goodrich (Terumo Corporation), Christopher D Hillyer (New York Blood Center),
Heather A Hume (Canadian Blood Services), Haresh Kirpalani (Children's Hospital of Philadelphia), Catherine S Manno (New York University), William Reed (Cellerant Therapeutics), Leslie E Silberstein (Boston Children's Hospital), Martha Sola-Visner (Boston Children's Hospital), Susan Stramer (American Red Cross), and Ronald G Strauss (University of lowa). K07 HL088921 (S.R.S.), K07 HL088922 (C.D.J.), K07 HL088923 (R.S.R.), K07 HL088968 (D.R.A.), P01 HL046925 (J.A.W.), and UL1RR024979 (J.A.W.); these are all grants from the National Institutes of Health, Bethesda, MD and Thrasher Research Fund, Salt Lake City, UT (J.A.W.).

Disclosure: J.A.W.: Consultant to Hemogenix, Loan Agreement for Use of Systemex Hematology Analyzer, and compensation for Systemex webinar. The other authors have no disclosures.

\section{REFERENCES}

1. Josephson CD, Glynn SA, Kleinman SH, Blajchman MA; State-of-the Science Symposium Transfusion Medicine Committee. A multidisciplinary "think tank": the top 10 clinical trial opportunities in transfusion medicine from the National Heart, Lung, and Blood Institute-sponsored 2009 stateof-the-science symposium. Transfusion 2011;51:828-41.

2. Widness JA. Pathophysiology of Anemia During the Neonatal Period, Including Anemia of Prematurity. Neoreviews 2008;9:e520.

3. Bell EF, Strauss RG, Widness JA, et al. Randomized trial of liberal versus restrictive guidelines for red blood cell transfusion in preterm infants. Pediatrics 2005;115:1685-91.

4. Kirpalani H, Whyte RK, Andersen C, et al. The Premature Infants in Need of Transfusion (PINT) study: a randomized, controlled trial of a restrictive (low) versus liberal (high) transfusion threshold for extremely low birth weight infants. J Pediatr 2006;149:301-7.

5. Whyte RK, Kirpalani H, Asztalos EV, et al.; PINTOS Study Group. Neurodevelopmental outcome of extremely low birth weight infants randomly assigned to restrictive or liberal hemoglobin thresholds for blood transfusion. Pediatrics 2009;123:207-13.

6. McCoy TE, Conrad AL, Richman LC, Lindgren SD, Nopoulos PC, Bell EF. Neurocognitive profiles of preterm infants randomly assigned to lower or higher hematocrit thresholds for transfusion. Child Neuropsychol 2011;17:347-67.

7. Nopoulos PC, Conrad AL, Bell EF, et al. Long-term outcome of brain structure in premature infants: effects of liberal vs restricted red blood cell transfusions. Arch Pediatr Adolesc Med 2011;165:443-50.

8. Fergusson DA, Hébert P, Hogan DL, et al. Effect of fresh red blood cell transfusions on clinical outcomes in premature, very low-birth-weight infants: the ARIPI randomized trial. JAMA 2012;308:1443-51.

9. Patel RM, Josephson CD. Storage age of red blood cells for transfusion of premature infants. JAMA 2013;309:544-5.

10. Setzer ES, Webb IB, Wassenaar JW, Reeder JD, Mehta PS, Eitzman DV. Platelet dysfunction and coagulopathy in intraventricular hemorrhage in the premature infant. J Pediatr 1982;100:599-605.

11. Andrew M, Castle V, Saigal S, Carter C, Kelton JG. Clinical impact of neonatal thrombocytopenia. J Pediatr 1987;110:457-64.

12. Kahn DJ, Richardson DK, Billett HH. Association of thrombocytopenia and delivery method with intraventricular hemorrhage among very-lowbirth-weight infants. Am J Obstet Gynecol 2002;186:109-16.

13. Lupton BA, Hill A, Whitfield MF, Carter CJ, Wadsworth LD, Roland EH. Reduced platelet count as a risk factor for intraventricular hemorrhage. Am J Dis Child 1988;142:1222-4.

14. Ghevaert C, Campbell K, Walton J, et al. Management and outcome of 200 cases of fetomaternal alloimmune thrombocytopenia. Transfusion 2007;47:901-10.

15. Andrew M, Vegh P, Caco C, et al. A randomized, controlled trial of platelet transfusions in thrombocytopenic premature infants. J Pediatr 1993;123:285-91.

16. Kahn DJ, Richardson DK, Billett HH. Inter-NICU variation in rates and management of thrombocytopenia among very low birth-weight infants. J Perinatol 2003;23:312-6.

17. Del Vecchio A, Sola MC, Theriaque DW, et al. Platelet transfusions in the neonatal intensive care unit:factors predicting which patients will require multiple transfusions. Transfusion 2001;41:803-8. 
18. Garcia Maria G, Duenas E, Sola MC, Hutson A, Theriaque D, Christensen RD. Epidemiologic and outcome studies of patients who received platelet tranfusions in the neonatal intensive care unit. J Perinatol 2001;21:415-20.

19. Josephson CD, Su LL, Christensen RD, et al. Platelet transfusion practices among neonatologists in the United States and Canada: results of a survey. Pediatrics 2009;123:278-85.

20. Kenton AB, Hegemier S, Smith EO, et al. Platelet transfusions in infants with necrotizing enterocolitis do not lower mortality but may increase morbidity. J Perinatol 2005;25:173-7.

21. Baer VL, Lambert DK, Henry E, Snow GL, Sola-Visner MC, Christensen RD. Do platelet transfusions in the NICU adversely affect survival? Analysis of 1600 thrombocytopenic neonates in a multihospital healthcare system. J Perinatol 2007;27:790-6.

22. Bonifacio L, Petrova A, Nanjundaswamy S, Mehta R. Thrombocytopenia related neonatal outcome in preterms. Indian J Pediatr 2007;74:269-74.

23. Bateman ST, Lacroix J, Boven K, et al.; Pediatric Acute Lung Injury and Sepsis Investigators Network. Anemia, blood loss, and blood transfusions in North American children in the intensive care unit. Am J Respir Crit Care Med 2008;178:26-33.

24. Spinella PC, Dressler A, Tucci M, et al.; Pediatric Acute Lung Injury and Sepsis Investigators Network. Survey of transfusion policies at US and Canadian children's hospitals in 2008 and 2009. Transfusion 2010;50:2328-35.

25. Lacroix J, Hébert PC, Hutchison JS, et al.; TRIPICU Investigators; Canadian Critical Care Trials Group; Pediatric Acute Lung Injury and Sepsis Investigators Network. Transfusion strategies for patients in pediatric intensive care units. N Engl J Med 2007;356:1609-19.

26. Spinella PC, Sparrow RL, Hess JR, Norris PJ. Properties of stored red blood cells: understanding immune and vascular reactivity. Transfusion 2011;51:894-900.

27. Slonim AD, Joseph JG, Turenne WM, Sharangpani A, Luban NL. Blood transfusions in children: a multi-institutional analysis of practices and complications. Transfusion 2008;48:73-80.

28. Pisciotto PT. Blood transfusions in children: pediatric transfusion practices beyond the neonatal period. Transfusion 2008;48:8-9.

29. Gauvin F, Champagne MA, Robillard P, Le Cruguel JP, Lapointe H, Hume $\mathrm{H}$. Long-term survival rate of pediatric patients after blood transfusion. Transfusion 2008;48:801-8.

30. Kamper-Jørgensen M, Edgren G, Rostgaard K, et al. Blood transfusion exposure in Denmark and Sweden. Transfusion 2009;49:888-94.

31. Boghossian NS, Hansen NI, Bell EF, et al.; Eunice Kennedy Shriver National Institute of Child Health and Human Development Neonatal Research Network. Survival and morbidity outcomes for very low birth weight infants with Down syndrome. Pediatrics 2010;126:1132-40.

32. Fitzgibbons SC, Ching Y, Yu D, et al. Mortality of necrotizing enterocolitis expressed by birth weight categories. J Pediatr Surg 2009;44:1072-5; discussion 1075-6.

33. Hintz SR, Kendrick DE, Stoll BJ, et al.; NICHD Neonatal Research Network. Neurodevelopmental and growth outcomes of extremely low birth weight infants after necrotizing enterocolitis. Pediatrics 2005;115:696-703.

34. Grave GD, Nelson SA, Walker WA, et al. New therapies and preventive approaches for necrotizing enterocolitis: report of a research planning workshop. Pediatr Res 2007;62:510-4.

35. Lin PW, Stoll BJ. Necrotising enterocolitis. Lancet 2006;368:1271-83.

36. Lin PW, Nasr TR, Stoll BJ. Necrotizing enterocolitis: recent scientific advances in pathophysiology and prevention. Semin Perinatol 2008;32:70-82.

37. Neu J, Walker WA. Necrotizing enterocolitis. N Engl J Med 2011;364:25564.

38. Patel RM, Denning PW. Therapeutic use of prebiotics, probiotics, and postbiotics to prevent necrotizing enterocolitis: what is the current evidence? Clin Perinatol 2013;40:11-25.

39. Blau J, Calo JM, Dozor D, Sutton M, Alpan G, La Gamma EF. Transfusionrelated acute gut injury: necrotizing enterocolitis in very low birth weight neonates after packed red blood cell transfusion. J Pediatr 2011;158:403-9.

40. Paul DA, Mackley A, Novitsky A, Zhao Y, Brooks A, Locke RG. Increased odds of necrotizing enterocolitis after transfusion of red blood cells in premature infants. Pediatrics 2011;127:635-41.
41. Christensen RD, Lambert DK, Henry E, et al. Is "transfusion-associated necrotizing enterocolitis" an authentic pathogenic entity? Transfusion 2010;50:1106-12.

42. Mohamed A, Shah PS. Transfusion associated necrotizing enterocolitis: a meta-analysis of observational data. Pediatrics 2012;129:529-40.

43. Kirpalani H, Zupancic JA. Do transfusions cause necrotizing enterocolitis? The complementary role of randomized trials and observational studies. Semin Perinatol 2012;36:269-76.

44. Roberts IA. The changing face of haemolytic disease of the newborn. Early Hum Dev 2008;84:515-23.

45. Tormey CA, Stack G. The persistence and evanescence of blood group alloantibodies in men. Transfusion 2009;49:505-12.

46. Nordvall M, Dziegiel M, Hegaard HK, et al. Red blood cell antibodies in pregnancy and their clinical consequences: synergistic effects of multiple specificities. Transfusion 2009;49:2070-5.

47. Zimring JC, Welniak L, Semple JW, Ness PM, Slichter SJ, Spitalnik SL; NHLBI Alloimmunization Working Group. Current problems and future directions of transfusion-induced alloimmunization: summary of an NHLBI working group. Transfusion 2011;51:435-41.

48. Thompson AA, Cunningham MJ, Singer ST, et al.; Thalassemia Clinical Research Network Investigators. Red cell alloimmunization in a diverse population of transfused patients with thalassaemia. $\mathrm{Br} J$ Haematol 2011;153:121-8.

49. Michail-Merianou V, Pamphili-Panousopoulou L, Piperi-Lowes L, Pelegrinis E, Karaklis A. Alloimmunization to red cell antigens in thalassemia: comparative study of usual versus better-match transfusion programmes. Vox Sang 1987;52:95-8.

50. Spanos T, Karageorga M, Ladis V, Peristeri J, Hatziliami A, Kattamis C. Red cell alloantibodies in patients with thalassemia. Vox Sang 1990;58:50-5.

51. Singer ST, Wu V, Mignacca R, Kuypers FA, Morel P, Vichinsky EP. Alloimmunization and erythrocyte autoimmunization in transfusion-dependent thalassemia patients of predominantly asian descent. Blood 2000;96:336973.

52. Chou ST, Liem RI, Thompson AA. Challenges of alloimmunization in patients with haemoglobinopathies. Br J Haematol 2012;159:394-404.

53. Vichinsky EP, Ohene-Frempong K; Transfusion Committee. Approaches to transfusion therapy and iron overload in patients with sickle cell disease: results of an international survey. Pediatr Hematol Oncol 2011;28:37-42.

54. Lasalle-Williams M, Nuss R, Le T, et al. Extended red blood cell antigen matching for transfusions in sickle cell disease: a review of a 14-year experience from a single center (CME). Transfusion 2011;51:1732-9.

55. Wilkinson K, Harris S, Gaur P, et al. Molecular blood typing augments serologic testing and allows for enhanced matching of red blood cells for transfusion in patients with sickle cell disease. Transfusion 2012;52:381-8.

56. Ribeiro KR, Guarnieri MH, da Costa DC, Costa FF, Pellegrino J Jr, Castilho L. DNA array analysis for red blood cell antigens facilitates the transfusion support with antigen-matched blood in patients with sickle cell disease. Vox Sang 2009;97:147-52.

57. Bianchi DW, Zickwolf GK, Weil GJ, Sylvester S, DeMaria MA. Male fetal progenitor cells persist in maternal blood for as long as 27 years postpartum. Proc Natl Acad Sci USA 1996;93:705-8.

58. Dunsford I, Bowley CC, Hutchison AM, Thompson JS, Sanger R, Race RR. A human blood-group chimera. Br Med J 1953;2:81.

59. Adams KM, Nelson JL. Microchimerism: an investigative frontier in autoimmunity and transplantation. JAMA 2004;291:1127-31.

60. Lee TH, Paglieroni T, Ohto H, Holland PV, Busch MP. Survival of donor leukocyte subpopulations in immunocompetent transfusion recipients: frequent long-term microchimerism in severe trauma patients. Blood 1999;93:3127-39.

61. Sanchez R, Lee TH, Wen L, et al. Absence of transfusion-associated microchimerism in pediatric and adult recipients of leukoreduced and gammairradiated blood components. Transfusion 2012;52:936-45.

62. Marshall C, Zwerdling T, Dwyre DM, Montalvo L, Lee T-H, Busch M. Transfusion-associated microchimerism, hemoglobinopathy and autoimmune disease. Transfusion 2007;47:110A-1A.

63. Selvarajah S, Busch MP. Transfusion transmission of HCV, a long but successful road map to safety. Antivir Ther (Lond) 2012;17(7 Pt B):1423-9. 


\section{Pediatric transfusion medicine research ReView}

64. Hillyer CD, Blumberg N, Glynn SA, Ness PM; NHLBI Working Group in Transfusion Recipient Epidemiology and Outcomes Research. Transfusion recipient epidemiology and outcomes research: possibilities for the future. Transfusion 2008;48:1530-7.

65. AuBuchon JP, Whitaker BI. America finds hemovigilance! Transfusion 2007;47:1937-42.

66. Ziemann M, Krueger S, Maier AB, Unmack A, Goerg S, Hennig H. High prevalence of cytomegalovirus DNA in plasma samples of blood donors in connection with seroconversion. Transfusion 2007;47:1972-83.

67. Herwaldt BL, Linden JV, Bosserman E, Young C, Olkowska D, Wilson M. Transfusion-associated babesiosis in the United States: a description of cases. Ann Intern Med 2011;155:509-19.

68. Simonsen KA, Harwell JI, Lainwala S. Clinical presentation and treatment of transfusion-associated babesiosis in premature infants. Pediatrics 2011;128:e1019-24.

69. Stramer SL, Linnen JM, Carrick JM, et al. Dengue viremia in blood donors identified by RNA and detection of dengue transfusion transmission during the 2007 dengue outbreak in Puerto Rico. Transfusion 2012;52: 1657-66.

70. Dumont LJ, Kleinman S, Murphy JR, et al. Screening of single-donor apheresis platelets for bacterial contamination: the PASSPORT study results. Transfusion 2010;50:589-99.

71. Pearce S, Rowe GP, Field SP. Screening of platelets for bacterial contamination at the Welsh Blood Service. Transfus Med 2011;21:25-32.
72. Walther-Wenke G, Wirsing von König CH, Däubener W, et al.; Working Party on Bacteria Safety in Transfusion Medicine, Advisory Board of the German Ministry of Health, Berlin. Monitoring bacterial contamination of blood components in Germany: effect of contamination reduction measures. Vox Sang 2011;100:359-66.

73. Lin L, Cook DN, Wiesehahn GP, et al. Photochemical inactivation of viruses and bacteria in platelet concentrates by use of a novel psoralen and long-wavelength ultraviolet light. Transfusion 1997;37:423-35.

74. McCullough J, Vesole DH, Benjamin RJ, et al. Therapeutic efficacy and safety of platelets treated with a photochemical process for pathogen inactivation: the SPRINT Trial. Blood 2004;104:1534-41.

75. Marschner S, Goodrich R. Pathogen Reduction Technology Treatment of Platelets, Plasma and Whole Blood Using Riboflavin and UV Light. Transfus Med Hemother 2011;38:8-18.

76. Asano H, Lee CY, Fox-Talbot K, et al. Treatment with riboflavin and ultraviolet light prevents alloimmunization to platelet transfusions and cardiac transplants. Transplantation 2007;84:1174-82.

77. Cazenave JP, Folléa G, Bardiaux L, et al. A randomized controlled clinical trial evaluating the performance and safety of platelets treated with MIRASOL pathogen reduction technology. Transfusion 2010;50:2362-75.

78. Josephson CD, Granger S, Assmann SF, et al. Bleeding risks are higher in children versus adults given prophylactic platelet transfusions for treatment-induced hypoproliferative thrombocytopenia. Blood 2012;120: $748-60$. 